\title{
Interactive comment on "Description and evaluation of a detailed gas-phase chemistry scheme in the TM5-MP global chemistry transport model (r112)" by Stelios Myriokefalitakis et al.
}

\section{Anonymous Referee \#2}

Received and published: 9 June 2020

The manuscript describes the implementation of the MOGUNTIA chemical mechanism, using KPP and Rosenbrock solver in the TM5 model and evaluates the improvements and differences with respect to the earlier versions of the model. The definition of the new mechanism is extensively described but the earlier versions of the model is mainly referring to older publications. I think these versions used in the manuscript could be described a little more to address the differences later. I find the manuscript easy to follow and an adequate level of English, which can be improved during the review. I have some general and specific comments which could be addressed in order to have the manuscript suitable to be published at GMD.

Printer-friendly version

Discussion paper 


\section{General Comments}

Additional analyses can be performed with regards to the transport of tracers as it is frequently used in the manuscript to explain differences. How good is the model with respect to transport, especially vertical transport?

\section{Specific Comments}

Page 4, lines 4-5: Use of $150 \mathrm{ppb}$, or any concentration level has caveats, e.g. model bias. Why not use the meteorological tropopause instead? The implications should be addressed.

Page 13, line 13. Use of different emissions are not clearly mentioned in section 2.4. Authors should justify the use of different emissions and how this impacts the changes they see in the different scenarios.

Page 20, line 3: It would be great if the results are compared with satellites.

Interactive comment on Geosci. Model Dev. Discuss., https://doi.org/10.5194/gmd-2020-110, 2020. 